\title{
Materia prima, hornos y utillaje en la producción de vidrio de la ciudad de México, siglo XVIII
}

Raw material, ovens and tools in production of glass in México City. Century XVIII

josé roberto peralta rodrícuez. Maestro en Ciencias, labora en la Sección de Estudios de Posgrado e Investigación de la Escuela Superior de Medicina del Instituto Politécnico Nacional. Sus líneas de investigación son: Desarrollo histórico de la atención a la salud visual en México y Producción de vidrio y lentes oftálmicos en la ciudad de México, siglos XVII-XIX. Publicaciones recientes: Vidrieros en la Cd. de México en el siglo XVIII. Sitios de producción y comercialización. Procesos Históricos (núm. 23, 2013). Boticarios, Boticas y Vidrieros en la Nueva España, Cd. de México Siglo XVI. Acta Médica (Vol. 2 (2) 2014).

RESUMEN. Vidrieros novohispanos adecuaron la producción de vidrio a recursos y condiciones del entorno. La pureza del material pétreo y sal vegetal debió atenderse con esmero puesto que influía en la calidad del vidrio. El primer componente pudo obtenerse de haciendas dedicadas a procesar rocas con minerales y de “caleras”, el segundo, de calidad diversa por variantes de la planta fue sustituido posteriormente por tequexquite y salitre, no obstante con estos últimos se fabricaba pólvora y "agua fuerte". Aunque la arquitectura de los hornos fue similar a la ibérica, el material de construcción no lo fue así; el utillaje asimismo fue semejante. El análisis de requerimientos para la fabricación de vidrio conduce a reconocer la magnitud de la inversión económica necesaria, circunstancia que influyó para que esta actividad prosperara en la ciudad de México.

PALABRAS CLAVE. Vidrio novohispano, barrilla, tequexquite, salitre, hornos de vidrio; Nueva España, siglo XVIII

ABSTRACT. The glass makers from New Spain adapted their production to local resources and conditions. The purity of materials (minerals and vegetable salt) was a matter of attention as it influenced in the quality of glass. The first were obtained from haciendas and caleras devoted to mineral processing and the second was soon replaced by local tequexquite and saltpetre. Oven architecture and tools were similar to those from Spain. The analysis of glass production conditions allows for a survey of its investment requirements and of the circumstances that permitted its prosperity in Mexico City.

KEYWORDS. glass from New Spain; nitre; furnace of glass; Century XVIII

\section{INFORMACIÓN DEL ARTÍCULO}

Recibido: 2 de febrero de 2016

Aceptado: 16 de junio de 2018

Correo para correspondencia: jperaltaro@ipn.mx / rperaltar@gmail.com

Agradecimientos: La realización del presente trabajo fue apoyado económicamente por la Secretaría de Investigación y Posgrado del Instituto Politécnico Nacional y la Comisión de Fomento de Actividades Académicas del IPN 


\section{Materia prima, hornos y utillaje en la producción de vidrio de la ciudad de México, siglo XVIII}

JOSÉ ROBERTO PERALTA RODRÍGUEZ

El establecimiento de conquistadores, colonizadores y gobernantes en la Nueva España trajo consigo demanda de diversos productos acordes a su estilo de vida peninsular, para ello se adiestró a indígenas en la fabricación de algunos de ellos, otros fueron generados por artesanos migrantes o bien importados de ultramar. Estas condiciones promovieron actividades artesanales e industriales en las que se manifestaba el fundamento de los aspectos de producción, habilidad manual y nivel tecnológico alcanzado. Algunos artículos elaborados localmente con diversos materiales pasaron a formar parte del ajuar doméstico de acaudalados comerciantes, gobernantes y de los principales espacios dedicados al culto religioso, ante los detalles excelsos logrados.

La manufactura de artículos de vidrio se instauró en la ciudad de México ante la necesidad de fabricar vasijas denominadas "cornamuzas” empleadas en la separación de metales, el importarlas implicaba riesgo por su fragilidad y alto costo de inversión, lo que determinó la incorporación de vidrieros a la actividad metalúrgica ${ }^{1}$. Estos artífices diversificaron su quehacer hacia la elaboración de diferentes recipientes y envases demandados por boticarios y médicos ${ }^{2}$, así como otros artículos de uso exclusivo de la aristocracia como candiles, lentes para anteojos, espejos y otros más ${ }^{3}$.

1 Bargalló (1966, pp.97-98).

2 Archivo General de la Nación (en adelante AGN) Casa de Moneda, Vol. 242,f. 129, 180.

3 AGN Matrimonios, Vol. 53, exp.17, ff. 197-198v

AGN Matrimonios, Vol. 122, exp. 25, ff. 87-90.

Archivo General de Notarias, vol. 376, ff. 99.

AGN Matrimonios Vol. 10, exp. 1287, ff.290. 
El grupo de vidrieros en de esta ciudad, reducido en comparación con otros conjuntos de artesanos, era de 115 entre los años de 1566 y 1790; hasta este momento no ha sido posible precisar la existencia de su gremio. La zona que habitaban correspondía a la periferia del oriente de la capital, donde se encontraban dos de tres sitios de producción vidriera con capacidad reducida de fabricación y el restante con infraestructura industrial y económica para que fuera continua, sistemática y considerable ${ }^{4}$. Es de suponerse que estos menestrales pudieron estar vinculados con loceros por la semejanza del material empleado, hornos de producción, proximidad de sus instalaciones y por la existencia del nombramiento de Maestro de Mayor de vidrio y loza fina de un artífice que laboraba en la ciudad de Puebla ${ }^{5}$, aunque este nombramiento no ha sido reconocido en maestros vidrieros de la ciudad de México. Por otra parte aunque los sitios de manufactura de loza se encontraban al oriente de la ciudad $^{6}$, los de vidrio estaban retirados de ellos, lo único que compartían loceros y vidrieros era la pobreza, puesto que el salario bajo solo les permitía vivir en condiciones de penuria en la zona referida.

La materia prima empleada por ambos artesanos contenía el elemento químico de silicio que junto con la plata, cobre, plomo, zinc, fierro, níquel, sodio, potasio y otros metales conformaban la arcilla, pedrusco de rocas sedimentaria e ígnea, las primeras localizadas a orillas de ríos y lagos, valles y fondos de barrancas, y las segundas ubicadas debajo de la corteza terrestre. La mayor o menor cantidad de silicio mezclado con otros minerales del material pétreo determinaba el color de la argamasa empleada para la cerámica a configurarse mediante el torno y en frío, para el caso del vidrio, se moldeaba a base de calor y era imprescindible el sodio, potasio y calcio. La materia prima para ambos tipos debió extraerse muy probablemente de diferente sitio lo que determinaba la proporción y tipos de minerales que condicionaba las características físicas de opacidad, transparencia, porosidad, color, resistencia, peso y otras más, según fuera cerámica o vidrio. El proceso de purificación de los

\footnotetext{
4 Peralta (2011, pp. 34-72).

5 Castro (2004, pp. 51-67).

6 Castillo (2007, p. 18).
} 
componentes químicos y la temperatura necesaria para la fusión de la materia vítrea diferían a los requeridos para la loza, mayólica y porcelana.

Artículos de vidrio eran importados a la ciudad de México de la península ibérica y países centroeuropeos aún de la presencia de vidrieros locales y extranjeros. Existen evidencias de que a partir del segundo periodo del siglo XVIII provenían de la Real Fábrica de Cristales de la Granja de San Ildefonso ${ }^{7}$ y de la ciudad de Bohemia, ésta importaba sus productos hacia España a partir de la segunda mitad del siglo XVII, todos embarcados en el puerto de Cádiz por comerciantes españoles independientes para distribuirlas en ciudades del nuevo continente ${ }^{8}$.

Los objetos del material referido fueran de ornato o uso hogareño tenían alto costo económico por lo que formaban parte del ajuar doméstico del estrato social novohispano con capacidad de adquisición, no obstante piezas manufacturadas localmente con diferente calidad, terminado y patrones de forma semejantes a los provenientes del exterior, pasaron a formar parte lentamente de la vida doméstica cotidiana del resto de la sociedad novohispana como puede apreciarse en representaciones pictóricas del siglo XVIII además de piezas integras y fragmentos recuperados de rescates arqueológicos. El reconocimiento de las propiedades físicas y químicas del vidrio favorecieron su uso en otras actividades importantes ${ }^{9}$.

Ante la existencia reducida y dispersa de la información concerniente al proceso de fabricación del vidrio en la ciudad de México durante la época virreinal, el presente documento tiene como propósito presentar un mecanismo explicativo de esta actividad a partir del análisis de las características que debió reunir la materia prima y del proceso implicado para obtener sus cualidades de calidad así como de las instalaciones físicas singulares mediante las que se lograba la integración química de la masa vítrea y además de los utensilios específicos que empleaba el diestro artesano. Asimismo esta reflexión permite comprender las implicaciones económicas que conllevaba la instalación de la

7 Pastor (1994, pp. 35-75).

8 Stepánek (2000, pp. 201-203); Bohumil (1964, pp. 24-26).

9 Peralta (2010, pp. 1-20); Boticarios (2014, pp. 73-78); Peralta (2011, pp. 15-57). 
actividad productiva y como todo ello influyó para que no se desarrollara como otras labores artesanales en la época referida.

MATERIA PRIMA

Los vidrieros consideraban como elementos relevantes a la arena (procedente de lechos de ríos), sal vegetal y diversos minerales presentes en el material pétreo, aunque carecían del pleno conocimiento de la esencia química que determinaba las funciones de cada uno de ellos. Este saber se mantuvo en forma reservada así como las proporciones y pureza de los constituyentes de la materia prima y del proceso requerido para integrarlos, erudición lograda a través del tiempo que condujo a obtener objetos de calidad.

La arcilla (integrante de algunos tipos de arena) era la fuente de sílice y conformaba la mayor parte de la materia vítrea; facilitaba la cohesión del resto de integrantes y otorgaba resistencia mecánica. Los artesanos apreciaban la de coloración blanca por carecer de otros minerales que alteraban la coloración del vidrio, de lo contrario condicionaba mayor requerimiento de temperatura para la fusión, lo que demandaba más leña y generaba deterioro prematuro de los hornos. Para evitar lo anterior se dieron a la tarea de reconocer sitios específicos de obtención en el territorio virreinal o pagaban para que fuera de calidad $^{10}$.

El proceso al que se sometía la arcilla fue el lavado inicial a fin de reducir impurezas, una de las razones por la que los sitios de producción hasta ahora localizados en la ciudad de México, se ubicaban adjuntos a acequias. A continuación se realizaba la pulverización mediante molino y su cernido para obtener partículas de tamaño reducido lo que facilitaba la reactividad entre los constituyentes de la materia referida por ello se considera que muy probablemente los sitios mineros trituraban y proporcionaban este material.

El componente considerado fundamental fue la "sal" de tipo sódico con función de fundente y que se obtenía del vegetal denominado "barrilla", término genérico y popular, aunque por sus particularidades se le llamó "barrilla

10 AGN, Casa de Moneda, Vol. 502 ff.1, 3v, 28v. 
fina". Se identificaba por su color, sabor y olor una vez obtenida ${ }^{11}$; variedades de este vegetal diferían en el aporte cuantitativo y cualitativo de los compuestos químicos por lo que en ocasiones se usaban propositivamente, aunque la calidad del vidrio disminuía o bien sustituían a la de tipo fino con el fin de estafar ${ }^{12}$.

La referencia más antigua de la época colonial que expresa el uso de esta planta para la elaboración de vidrio es la que aparece en el libro de José Corona Núñez de 1579 titulado "Relaciones geográficas de la Diócesis de Michoacán, 1579-1580", en él se manifiesta que: "se cria gran suma de yerba de que se age el vidrio que los naturales llaman curiraxaqua: vienen los que hagen vidro de la ciudad de Mexico a cojella y la lleban en panes"13. Específicamente el término de barrilla y su uso aparece en la ordenanza de 1596 que resalta su importancia ya que con ella se superaba la calidad de las piezas de vidrio producidas hasta ese momento. Asimismo, indica la penalización por no proporcionarla a los vidrieros o la apropiación de gran volumen para controlar el precio de venta ${ }^{14}$, práctica monopólica suscitada también en España, por ello el establecimiento de disposiciones para preservar la planta referida ${ }^{15}$ conocida en diferentes puntos del continente americano ${ }^{16}$.

Precisar el tipo de barrilla dentro del reino vegetal llevó varios siglos, pues se le daba este término generalizado a toda aquella planta que proporcionaba sal con la que se fabricaba vidrio, jabón, agente blanqueante de textiles y empleada para cauterizar heridas ${ }^{17}$. Los vegetales a partir de los que se pudo obtener componentes sódicos ésta materia prima fueron varias, actualmente se han identificado tan solo 23 géneros de la familia de quenopodiácea, entre ellos el de Halogetum sativus de quien se extraía la mayor cantidad de sodio, por

11 De Herrera (1818, pp. 2050-255).

12 Velasco (2004, pp. 145-158).

13 Acuña (1987. p. 86).

14 AGN. Reales Cédulas Dupl. Vol.3, exp. 161, ff. 120-122.

15 Velasco (2004, pp. 145-168).

16 Paz (1862, t. I, p. 190); De Odriozola (1872, t. I, pp. 19, 124); De Herrera (1818, pp. 250-254).

17 Sala (2003, p. 69). 
lo que los artesanos se referían a la "barrilla fina" ${ }^{18}$. El cuadro núm. 1 muestra los términos comunes de algunas plantas barrilleras que pudieron utilizarse en el siglo XVIII.

\begin{tabular}{|c|c|c|}
\hline NOMBRE COMÚN & PAís & \\
\hline borde o espinosa ${ }^{58}$ & \multirow{14}{*}{ ESPAÑA } & \\
\hline Escobillosa 59 & & \\
\hline Pinchuda ${ }^{60}$ & & \\
\hline Salada 61 & & \\
\hline Salicor ${ }^{62}$ & & $\begin{array}{l}58 \text { De Herrera }(1818, \text { pp. } 259,260) \text {. } \\
59 \text { De Herrera }(1818 \text {, p. } 270) .\end{array}$ \\
\hline Sisallo ${ }^{63}$ & & 60 De Herrera $(1818$, p. 261). \\
\hline Tamojo $^{64}$ & & 61 De Herrera (1818, pp. 265, 266). \\
\hline Carambillo $^{65}$ & & $\begin{array}{l}62 \text { De Herrera }(1818, \text { p. } 256) \\
63 \text { De Herrera }(1818, \text { p. } 265)\end{array}$ \\
\hline Común 66 & & 64 De Herrera (1818, p. 269). \\
\hline Alacranera ${ }^{67}$ & & 65 De Herrera (1818, pp. 263-264). \\
\hline Fina o de Alicante ${ }^{68}$ & & $\begin{array}{l}66 \text { Don }(1900, \text { p. } 84) \\
67 \text { Don }(1900, \text { p. } 279)\end{array}$ \\
\hline Algazal o Gazul ${ }^{69}$ & & 68 Don (1900, p. 234). \\
\hline Sayones $^{70}$ & & 69 Townsend (1792, p. 131). \\
\hline Almarjo $^{71}$ & & $\begin{array}{l}70 \text { Townsend }(1792, \text { p. } 294) . \\
71 \text { Equilaz }(1886, \text { p. } 49) .\end{array}$ \\
\hline Maromera $^{72}$ & \multirow{3}{*}{ MÉXICO } & 72 Martínez (1979, pp. 172, 570). \\
\hline Romerito $^{73}$ & & 73 AGN. Casa de Moneda. Vol.46, \\
\hline Saladilla ${ }^{74}$ & & $\begin{array}{l}\text { exp.20,f259. } \\
74 \text { Santamaría (1943, p. 192). }\end{array}$ \\
\hline Verdolaguilla blanca ${ }^{75}$ & \multirow{2}{*}{ CUBA } & 75 Roig y Mesa (1928, pp. 78, 564). \\
\hline Criolla o yerba de vidrio ${ }^{76}$ & & 76 Dihigo (1946, pp. 19-110). \\
\hline Yerba del Vidrio $^{77} 78$ & PERÚ & $\begin{array}{l}77 \text { De Odriozola }(1872, \text { pp. } 19,124) . \\
78 \text { Carpancho }(1862, \text { p. } 190) .\end{array}$ \\
\hline Lechuga de $\operatorname{mar}^{79}$ & CENTROAMÉRICA & 79 Santamaría (1943, p. 192). \\
\hline
\end{tabular}

18 Fernández (1998, p. 3). 
Con respecto a su sitio de plantío el documento de Correa Núñez expresa que prosperaba en la laguna de Cuitzeo y la ordenanza comentada declara su labranza en Guyangareo, ambos sitios ubicados en la región agrícola de Michoacán, fundada alrededor de 1541 por Antonio de Mendoza ${ }^{19} 2021$, en ella quizás se cultivó alguna otra variante junto con el trigo, cebada, adormidera, comino y anís como costumbre peninsular ${ }^{22}$. Otro lugar de cultivo fue Xaltocan, ubicado al norte de la cuenca de México y rodeado de aguas con lechos salinos. En esta zona, según ordenanzas de 1796, los indígenas eran diestros en reconocerla y cosecharla, por ello se les exentó de trabajar en el desagüe en la ciudad de México, con el fin de dedicarse a su cultivo y cubrir la demanda solicitada por la Casa del Apartado en donde se producían cornamusas ${ }^{23}$.

El procesamiento de la barrilla, estaba a cargo del "barrillero", actividad registrada en la ciudad de México en 1790 y se iniciaba con el secado de la planta madura con raíz por dos semanas, condición en que se almacenaba hasta por dos años siempre y cuando se preservara de humedad. Una vez realizado lo anterior se procedía a incinerarse en temporada seca, lo que requería de 28 a 40 horas y se realizaba en una excavación circular con promedio de 1.5 a 2 $\mathrm{m}$. de diámetro y uno de profundidad, su interior se cubría con arcilla arenosa a la que se untaba líquido graso. En la superficie se colocaba una rejilla de metal sobre la que se distribuía la yerba, el fuego se ubicaba de tal forma que su combustión fuera completa, rápida y uniforme, el producto derretido caía al fondo, pero debería estar libre de yerba sin quemar o de cenizas; a menor cantidad de estos restos, mayor calidad del material. El producto obtenido se agitaba con palas de madera sin generar burbujas ${ }^{24}$, una vez terminada esta etapa se aguardaba a que la mezcla solidificara, lo que llevaba 48 horas e inclusive se dejaba hasta dos semanas o más; de 4 quintales de hierba que equivalía a $184 \mathrm{~kg}$., se generaba un quintal de piedra de barrilla de $46 \mathrm{~kg}$.; los

19 Acuña $(1987$, p. 86).

20 AGN. Reales Cedulas Dupl. Vol.3, exp. 161, ff. 120-122.

21 Herejón (202, pp. 46.49, 51).

22 Elcano (1940, pp. 454, 461); Carrera (1943, p. 543).

23 AGN, Casa de Moneda, Vol. 46, exp. 20 ff. 253, 259.

24 De Herrera (1818, pp. 243-247). 
barrilleros procuraban obtener de 200 a $300 \mathrm{~kg}$., cada vez que se realizaba el proceso $^{25}$. Una vez endurecida la pasta se fragmentaba para comercializarse, posteriormente los vidrieros trituraban y cernían el material para diluirlo en agua y someterla al fuego y así obtener la sal que se adicionaría al resto de los componentes; esta última etapa muy probablemente se realizó en el sitio de producción y bajo la supervisión del maestro vidriero.

Los vidrieros novohispanos ante dificultades para procesar $\mathrm{u}$ obtener la barrilla recurrieron a sustituirla por cenizas de álamo, pino, abedul, olmo y chopo, ya que aportaban compuestos potásicos en lugar de sódicos, aunque con ello se reducía lo diáfano del vidrio; este material fue utilizado en Europa antes de reconocer las ventajas del material sódico incluido en otros recursos naturales. En el siglo XVII se remplazaba a la planta referida por tequesquite ${ }^{26}$, tal vez por su obtención menos complicada y reconocimiento empírico de sus componentes sódicos y de carbono, puesto que sus características generales fueron reportadas para fines del siglo XVIII ${ }^{27}$. Al inicio del siguiente siglo se identificaron las variedades denominadas por su manifestación física: polvillo, costrilla y espumilla, así como el sitio exacto de extracción en el lago de México (de Texcoco), cuevas cercanas a Teotihuacán y Otumba, Puebla, Celaya, cerca de Guadalajara, San Luis Potosí, Zacatecas, Durango y Chihuahua ${ }^{28}$, para entonces se reportaba que la variante polvillo generaba la tenacidad del vidrio. Estudios muy posteriores demostraron la presencia de una variedad adicional presente en el lago de Texcoco, el confitillo; el análisis químico de todas induce a pensar que las más utilizadas fueron esta última y la espumilla, por su gran contenido de sesquicarbonato sódico ${ }^{29}$. Algunos vidrieros expresaron opiniones adversas de este componente ya que no otorgaba la transparencia al vidrio, sin embargo esto pudo deberse al contenido de materia orgánica y terrosa no eliminada mediante alguna técnica o bien se obtenía de sitio diferente. Esta eflorescencia mineral natural se empleaba también en el procesamiento de

25 Fernández (2002, pp. 315-330).

26 Suárez y Núñez (1780, t. IV, p. 215); Pastor (1994, p. 86).

27 Del Río (1795, p. 154).

28 Garcés (1802, pp. 1-8).

29 Talavera (1980. p. 3-15). 
textiles, en la metalurgia para sintetizar ácido nítrico o "agua fuerte" con el que se separaban metales, y para producir pólvora ${ }^{30}{ }^{31}$. Para esta última aplicación se requería purificarlo, lo que realizaba la Real Fábrica de Pólvora con alto costo económico; el explosivo era de vital importancia para el gobierno ya que se destinaba a los buques de guerra que escoltaban a los que transportaban mercancías, oro y plata hacía la península ibérica, los que en ocasiones eran interceptados por naves de origen inglés interesadas en los metales.

Otro ingrediente utilizado fue el calcio que se obtenía de cenizas de caliza, huesos y rocas sedimentarias de canteras con depósitos de microfósiles y caparazones del plancton, específicamente del tepetate blanco localizado en la cercanía del lago de Texcoco aportaba este elemento químico con función estabilizante de la reacción entre los integrantes. Desde la época prehispánica la cal u óxido de calcio se empleaba como material de construcción y en el proceso de nixtamalización, por lo que su obtención no fue complicada para los vidrieros. Al principio de la Colonia la cal se producía en Zumpango, Citlatépetl, Xaltocan, Tequixquiac y en Hueypoxtla; los españoles de la ciudad de México desde el siglo XVI demandaban de este último sitio su producción y habitantes de Xilotzingo compraban piedra caliza a este poblado para quemarla y comercializarla también, sin embargo posteriormente la cal se adquirió del sureste de Tula, Hidalgo ${ }^{32}$. Es importante considerar que las laderas de la cadena montañosa que rodeaban al lago de Texcoco contenían gran cantidad de carbonato de calcio dada su constitución de rocas ígneas y tobas volcánicas, sobre las que se encontraba el tepetate blanco.

La roca caliza extraída de canteras se calcinaba en hogueras abiertas y al aire libre llamadas "caleras" o en fosos de dos metros de diámetro y $50 \mathrm{~cm}$. de profundidad; se construían también hornos de piedra o arcilla hasta de ocho metros de diámetro, techados y ubicados bajo el nivel del suelo para reducir el consumo de energía para mantener por mayor tiempo la temperatura a

30 Flores (2006, pp. 43-62).

31 Díaz del Castillo (2002, pp. 285-389, 327); Humbolt (2004, pp. 449-455); Álvaro (1988, pp. 167-184).

32 Gibson (1970, pp. 342-343); Barba (1999, pp. 168-169); Gutiérrez (1999, pp. 11-19). 
semejanza de los hornos peninsulares de Toledo ${ }^{33}$. El proceso de calcinación debía realizarse a cierta temperatura de lo contrario se perdía la reactividad química, aquellos fragmentos que no alcanzaban este estado se retiraban y el remanente se cernía varias veces mediante malla fina para obtener fracciones lo más pequeñas posibles. Es probable que los vidrieros se valiesen del mármol para obtener este compuesto como los artesanos muranenses ${ }^{34}$.

Los metales incorporados en el material pétreo como el cobre, manganeso, hierro, estaño, níquel y otros proporcionaban color al vidrio según la proporción contenida, el conocimiento empírico alcanzado por algunos vidrieros permitía eliminar la acción de los metales o reforzarla al adicionar otros de manera intencionada para lograr cierta variedad de coloración o bien decolorarlo. Este saber condujo a la posibilidad de imitar el color de algunas piedras, por ello tanto en la península ibérica como en la Nueva España se promulgaron ordenanzas que prohibían a estos artífices la colocación de piezas de vidrio engastado en plata, oro u otro metal con el fin de evitar el fraude ${ }^{35}$; se desconoce hasta el momento sí alguno de origen novohispano contaba con dicha habilidad.

\section{HORNOS DE PRODUCCIÓN}

La información de las particularidades arquitectónicas de los hornos de vidrio en la ciudad de México es reducida, parte de ella es posible deducirla de los planos de la Casa del Apartado que datan de 1778, ya que eran al menos activos previamente al último tercio del siglo XVII; este sitio se ubicaba en el límite norte de la primera traza de la ciudad, adjunto a una acequia, en la "Calle de agua que va al monasterio de Santo Domingo" que más tarde se denominó "Calle del Apartado" ${ }^{36}$. Sumados a él existieron dos sitios más de fabricación registrados en 1748 y 1790, por el momento se desconocen sus

33 Palma (2010, pp. 227-234).

34 Suárez y Núñez (1780, t. IV, p. 237).

35 De Valle (1961, pp. 367-368); Cadiñanos (1999, p. 12).

36 Lombardo (1973, p. 159). 
características, existencia de restos arqueológicos y fecha precisa en que iniciaron su actividad. Otras referencias, aunque ajenas a nuestro país permiten tener idea de las particularidades de este tipo de instalación, una de ellas es la de Georgius Agricola de $1556^{37}$ y la restante es la descripción arquitectónica de restos arqueológicos de seis hornos de un taller de vidrio de finales del siglo XIII ubicado la región de Murcia, España ${ }^{38}$

Del documento de 1556 se infiere que el número de hornos en el taller de producción dependía de la solvencia económica del vidriero para establecer la factoría y mantener el volumen de objetos elaborados. Agricola expresa que eran necesarios tres de ellos para realizar el proceso, sin embargo al disponer de uno solo era posible lograrlo, aunque implicaba mayor tiempo en la ejecución de la tarea, menor número de trabajadores y por tanto volumen reducido de piezas generadas. El primer horno servía para la fusión de los integrantes de la materia prima; era de forma circular con techo abovedado, en su base y al centro se ubicaba la fosa para el fogón y se accedía a él por un corredor en pendiente, que iniciaba en una de las caras de la pared externa. Por arriba de este acceso y lateralmente se encontraba una oquedad para introducir el crisol que contendría "pasteladura vítrea" ${ }^{39}$. El material para la construcción de hornos era arcilla particular, las fuentes de información solo refieren el empleo de barro negro y blanco provenientes de diversos lechos fluviales, con ellos se fabricaban bloques de hasta $70 \mathrm{~cm}$. de grosor y se unían entre sí con el mismo tipo de material, una vez construido con estos bloques se recubría con ladrillo; los crisoles empleados también se fabricaban con este material ${ }^{40}$.

El segundo horno de diámetro aproximado de cuatro m. techado con bóveda y de dos m. de altura, contaba con fogón central y acceso a este. En sus paredes se encontraban varias oquedades de forma cuadrangular separadas entre sí a distancia similar, a través de las que se introducía el crisol para vaciar su contenido a los colocados en su interior e introducir la "caña", herramienta

37 Agricola (1950, pp. 704-804).

38 Muñoz (2006, pp. 469-472).

39 Agrícola (1950, pp. 704-804).

40 Mazadiego (2006, p. 71); Suárez y Núñez (1780, t. IV, p. 211); Rodríguez (1989, pp. 155.174). 
necesaria para tomar la materia vítrea a modelar, por lo que se le denominaba de trabajo (Fig. 1).

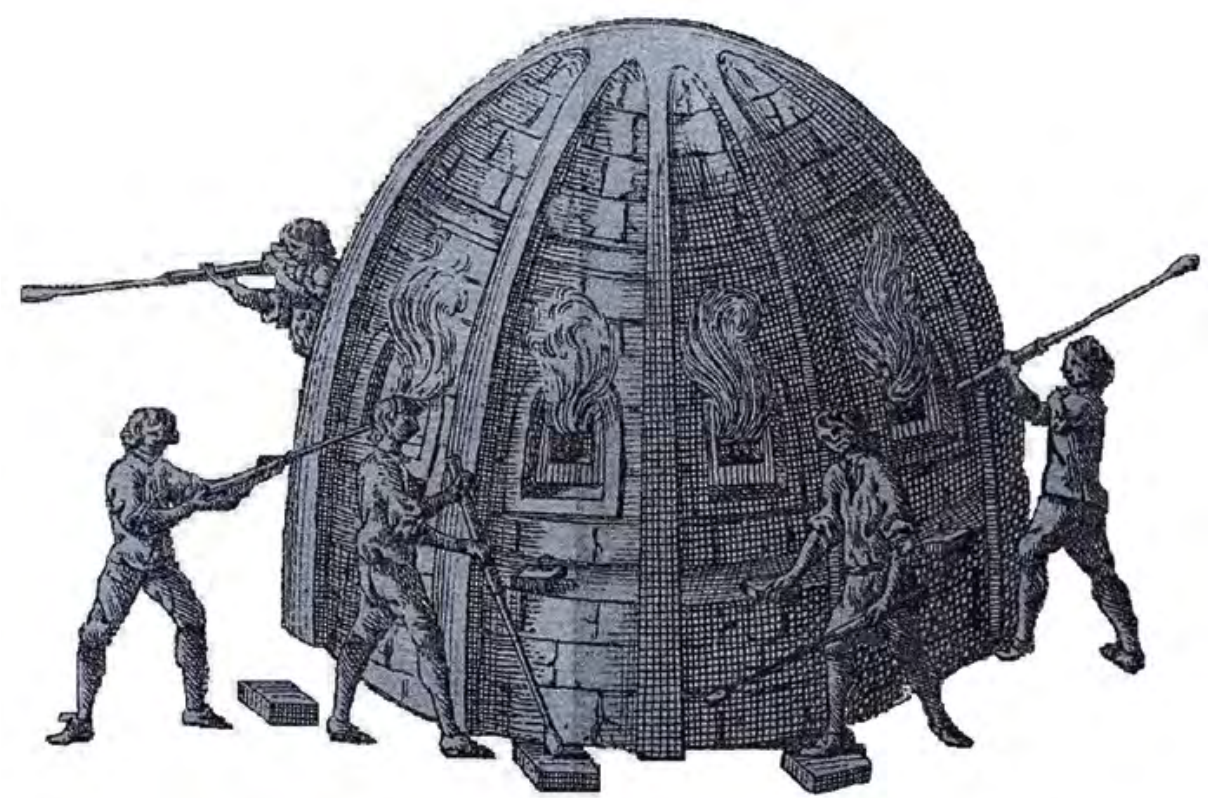

Fig. I. Grabado que muestra el "horno de trabajo" con oquedades de forma cuadrangular por las que introducían la "caña". El volumen de producción estaba supeditado al número de artesanos que trabajaban y dimensiones del horno. Fuente: Suárez y Núñez, I780.

Adjunto al descrito se encontraba un tercero que sería de templado, de forma rectangular con oquedades por las que se introducía las piezas ya modeladas y se colocaban sobre la plataforma horizontal que separaría al fogón (Fig. 2); la temperatura en él era menor con el fin de evitar el cambio brusco de ésta lo que generaba fragmentación de las piezas, después de cierto tiempo se extraían de él para almacenarse ${ }^{41}$.

41 Jiménez (1998, pp. 419-458). 


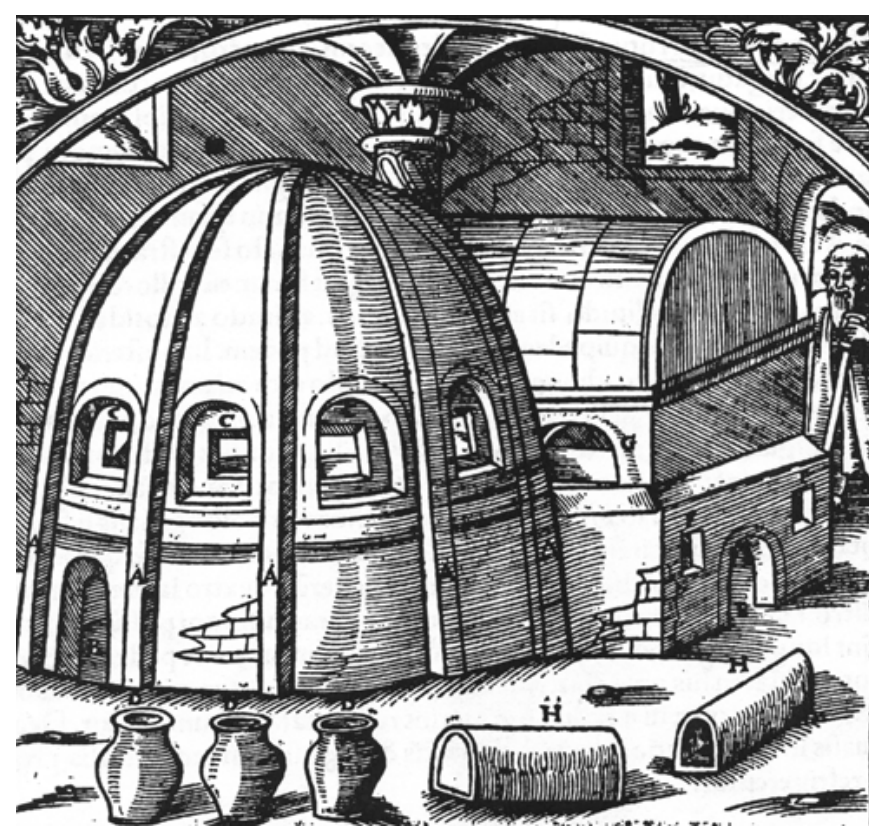

Fig. 2 Representación del horno de trabajo y de templado, este último de forma rectangular en que se colocaban las piezas ya modeladas previamente a su almacenamiento en bodegas. Fuente: Agricola, 1556 .

Los detalles mencionados al conjuntarse con la información de los cuatro hornos de vidrio que revelan los planos de la Casa del Apartado permiten concebir la imagen de esta zona de producción (Fig. 3). En dos espacios denominados la "Oficina de hornos de vidrios", con dimensiones de 27 varas de ancho por 17 de largo que equivaldría aproximadamente a la superficie de 383 $\mathrm{m}^{2} \mathrm{y}$ techados con tejamanil, se encontraban cuatro hornos separados por un muro pero con acceso entre sí. En una de ellas existían dos de forma circular de diámetro menor con tres aberturas y recámara lateral de forma rectangular, una adjunta y otra separada, con acceso propio e independiente; en la "oficina" restante se reconoce un horno de diámetro mayor con una abertura y sin recámara y otro de menor tamaño con tres aberturas y recámara agregada ${ }^{42}$. El

42 AGN. Casa de Moneda, Vol. 388, exp. 5, f.60v. 


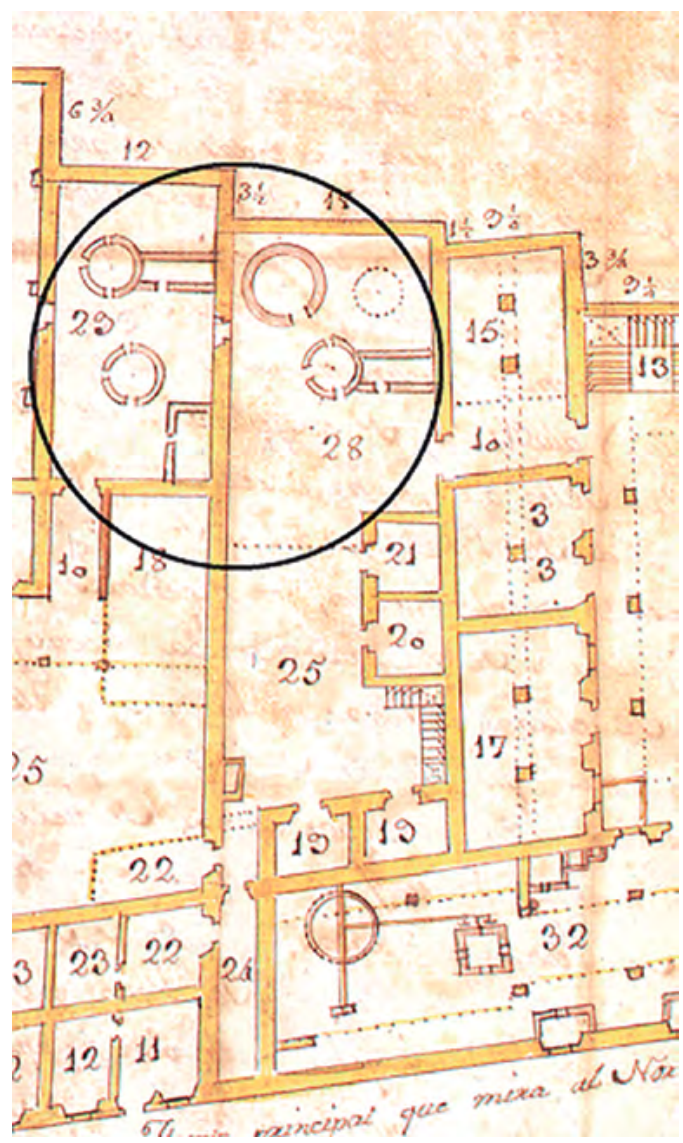

Fig. 3 Fracción del plano de la Casa del Apartado, el círculo negro delimita la "Oficina de hornos de vidrio" (28 y 29); las cifras que aparecen en la parte superior indican la longitud en varas castellanas. Cada espacio muestra la representación de los hornos de trabajo con tres accesos para depositar el material fundido o tomarlo de los crisoles; el de mayor diámetro era el destinado a la fusión. Adjunto a ellos se aprecia un espacio rectangular que sería el horno de enfriamiento; los números I5, I9 y 20 refieren bodegas de cornanuzas, vidrio y barrilla respectivamente. Fuente: AGN. Casa de Moneda, Vol. 388 , exp. 5, f. 60.

primero presenta la abertura que pareciera ser el umbral que conduce hacia el fogón o bien el espacio para introducir o extraer el crisol. Los tres hornos restantes de diámetro menor. 
Serían los de trabajo, sus aberturas probablemente estuvieron colocadas a una altura del nivel del piso que permitiría al artesano tomar fácilmente el material vítreo mediante la "caña", lo que condicionaría que el espacio destinado al fogón se ubicara por debajo del nivel del piso para mantener por mayor tiempo el calor necesario. Adicionalmente los espacios laterales permitían liberar el vapor generado en la cámara, aunque esto propiciaba que los artesanos estuvieran más expuestos a la alta temperatura propagada ${ }^{43}$. En relación a los de forma rectangular adjuntos a los de trabajo corresponderían al de templado (Fig.3).

Un aspecto que llama la atención respecto a la descripción de las características de los hornos y que no se constata en los planos, es la existencia de espacio específico para al fuelle o bien que la orientación del horno fuera tal que permitiera la entrada de corriente de aire que "avivara" el fuego e intensificara la combustión; se excluye ésta última condición puesto que se encontraban en espacios cerrados. Se desconoce el material con el que se construyeron estos hornos de la ciudad de México, únicamente se tiene referencia que los crisoles se fabricaban de roca porfídica muy refractaria, extraída de una cantera cercana a la ciudad de Pachuca, los que eran necesario remplazar por continuo deterioro ${ }^{44}$; la fuente energética empleada era leña seca de árboles belloteros y roble que proporcionaba mayor aporte térmico ${ }^{45}$, su transportación pudo ser por vía fluvial para reducir costos.

Al compararse la representación de los hornos de menor diámetro de la Casa del Apartado de 1778 (Fig.3) con el de Murcia $^{46}$ (Fig. 4A), se percibe similitud de su base y de los accesos laterales (Fig. 4B) y a su vez con las de Agricola del siglo XVI (Fig. 2). De lo anterior se deduce que los hornos de vidrio del siglo XVIII de la ciudad de México mantenían el diseño de los empleados en el siglo XVI y a su vez con los de tres siglos atrás en Europa, aunque muy probablemente variarían los materiales con los que se construían.

43 Suárez y Núñez (1780, t. IV, p. 224).

44 Humbolt (2004, p. 460).

45 Téofilo (2002, p. 47); Agrícola (1950, pp. 704-804).

46 Muñoz (1999, pp. 459-474); Jiménez (1998, pp. 419-458). 

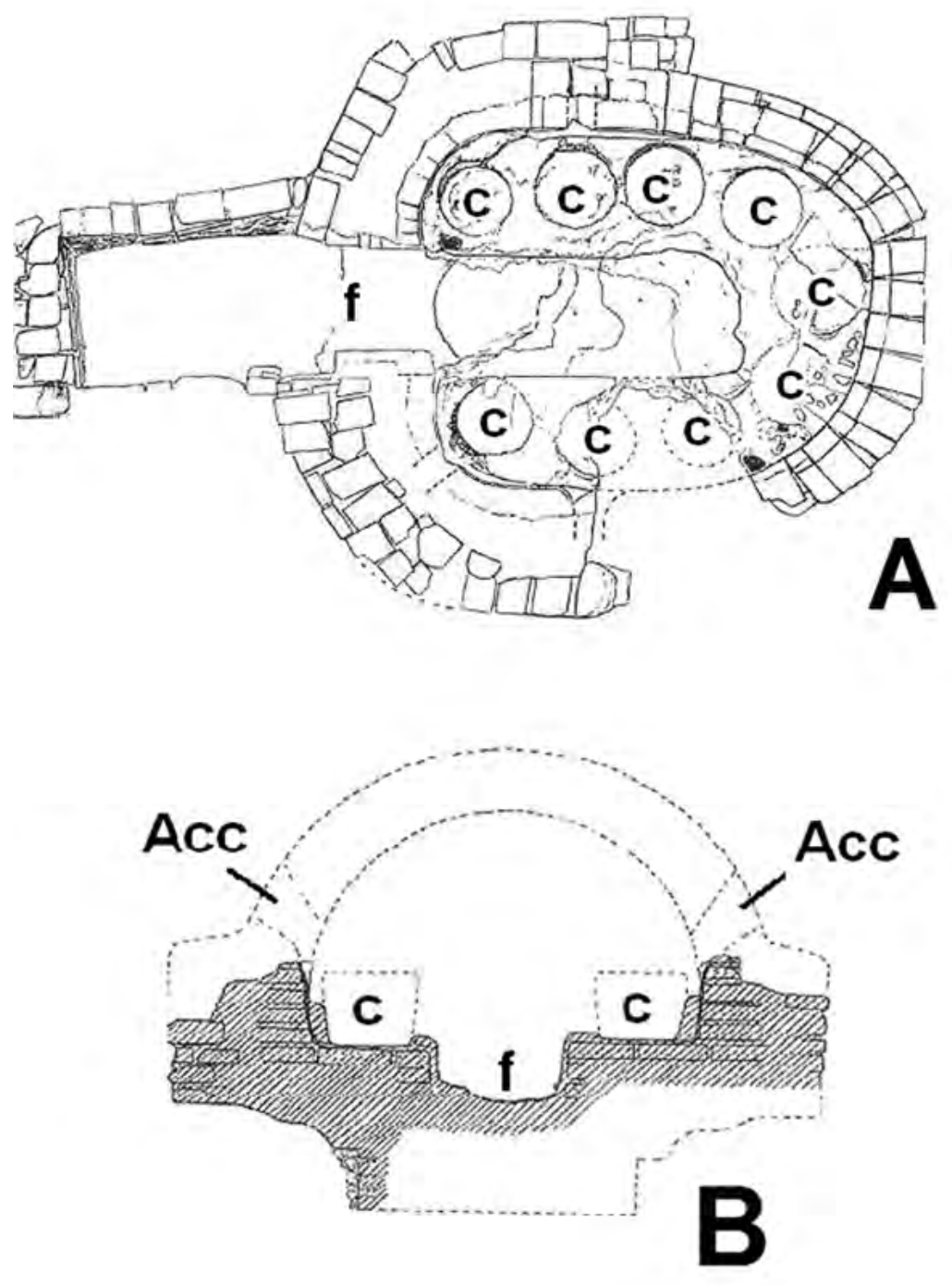

Fig. 4. Representación arquitectónica de un horno de producción localizado en Murcia. A. Vista de la planta del horno en ella se aprecia una banqueta en forma de "U" donde se encontraban restos de crisoles (c) con material vítreo; en posición central se ubicaba el fogón (f). B. Corte transversal en que la línea curva punteada muestra hipotéticamente la bóveda, en sus extremos se marca el acceso (ACC) al interior del horno y la ubicación de los crisoles (c) Fuente: Jiménez, I998 
Aunque el propósito de esta sección del documento no es realizar el análisis de los hornos empleados en diferentes actividades, es conveniente expresar que en la producción de cerámica también se empleó este recurso, sin embargo existió una variedad de ellos ${ }^{47}$ debido entre otros factores a la temperatura necesaria para lograr la cocción de la argamasa empleada, diferente a la requerida para la fusión de la materia vítrea. Una variante de ellos presenta características similares específicamente en el que se realizaba la fusión, ya que ambos eran bicamerales de base circular, con domo y parrilla, este elemento separaba ambas espacios ${ }^{48}$, el inferior destinado a concentrar el calor de la hoguera y el superior en la que se colocaba el crisol para fundir la masa vítrea, asimismo comparten el mismo diseño arquitectónico que el de los hornos árabes ${ }^{49}$, pero muy probablemente se diferenciaban es su material de construcción, aunque ambos se recubrían de ladrillo.

\section{HERRAMIENTAS}

Con respecto a estos utensilios los registros novohispanos son inexistentes hasta el momento, no obstante la reducida información de origen europeo auxilia a la comprensión de la última etapa de fabricación de artículos de vidrio.

Las herramientas requeridas por los vidrieros eran diversas, algunas de uso básico y otras de diseño singular de acuerdo a la especialidad del artesano que debieron ser forjadas por herreros, sin embargo ya que varias de ellas estarían expuestas a temperaturas de consideración debieron de tener porciones de madera para poderlas manejar.

Una vez colocada la materia prima en el crisol, se introducía al horno para lograr la integración de los ingredientes entre el rango de 500 a $1,500^{\circ} \mathrm{C}$ durante cinco horas, lapso en que algunos elementos químicos requerían menor o mayor temperatura para unirse entre sí. Durante este momento era necesario

47 Coll (2010, pp. 1-5. 17, 18).

48 Coll (2010, pp. 1-5. 17, 18).

49 Lister (1982, p. 81). 
agitar la mezcla mediante palas de hierro de mango largo ${ }^{50}$ y retirar burbujas con ayuda de la pala llamada "espumadera" también de metal aunque con varias perforaciones ${ }^{51}$, sus largas empuñaduras de madera se apoyaban en el soporte denominado "cabra" 52 que las mantenía en posición horizontal, con el fin de evitar fatiga y larga exposición del vidriero al calor intenso. Una vez que la materia vítrea alcanzaba su mayor fluidez, según la experiencia del artesano, se procedía a trasladar el crisol al horno de trabajo ${ }^{53}$ para vaciar el contenido a otros crisoles. A continuación un vidriero diferente introducía por las aberturas laterales una varilla de metal hueca de 120 a $180 \mathrm{~cm}$. de longitud denominada "caña", cuya tercera parte de este utensilio era de madera y en su extremo tenía una boquilla. Una vez que lograba retener un volumen determinado de la masa con el extremo de metal, extraía la caña para insuflar aire con la boca y formar una ampolla o vejiga, la que modelaría de acuerdo a la forma y grosor del objeto deseado. Este último ya modelado se separaba de la caña para fijarse al "puntil” (caña maciza), una vez adherida se colocaban aplicaciones adicionales de materia vítrea para confeccionar asas y diferentes realces con el fin de decorar la pieza. Para lograr esto último, se empleaba una variedad de pinzas y herramientas (Fig.5) e inclusive el artesano se acomodaba en un banco con descansa brazos que le permitía, una vez sentado, apoyar y mantener en forma horizontal el "puntil" y a la vez girarlo con el fin de colocar en la periferia del objeto aplicaciones que lo aderezaban o bien generar el cuello de un frasco o partes angostas en el envase o bien delinearlo con pinzas especiales e inclusive modificar la superficie.

Las placas de vidrio plano se obtenían a partir de una vejiga vítrea a la que se le daba forma de cilindro mediante movimiento oscilatorio de la caña y simultáneamente por lo viscoso de la vejiga incrementaba su longitud. El extremo opuesto a la boquilla se recortaba con el empleo de tijeras o una herramienta de forma semejante a un sable, a continuación con estas mismas se

50 Pastor (1994, p. 19).

51 Pastor (1994, p. 19).

52 Suárez y Núñez (1780, t. IV, p. 223).

53 Pastor (1994, p. 19). 

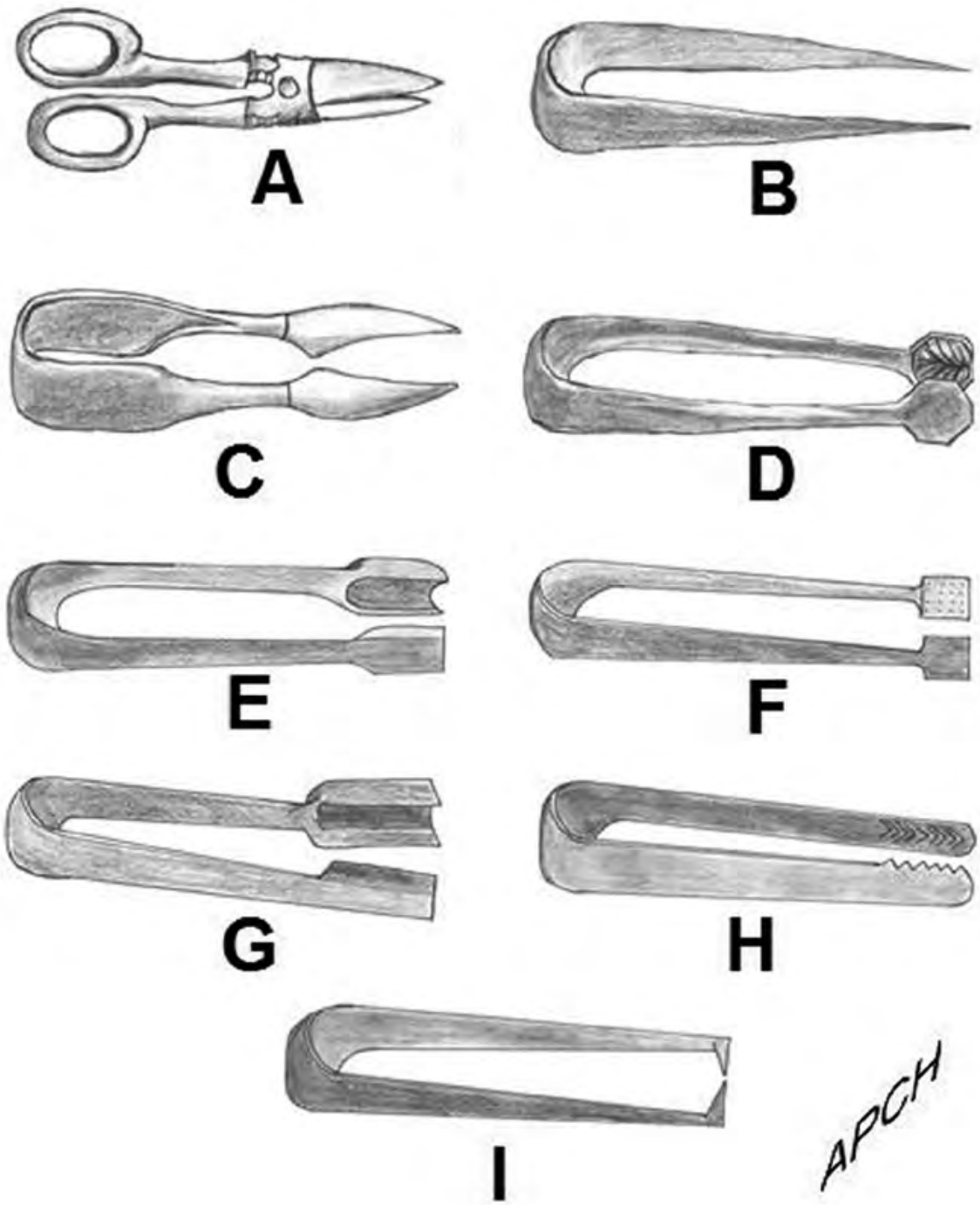

Fig. 5 Herramientas empleadas por vidrieros: tijeras (A), pincetas de punta (B), de concha (C), de flor (D), de asas moldeadas (E), planas (F), asas cuadradas lisas $(\mathrm{G})$, hoja de oliva $(\mathrm{H})$ y para generar perforaciones (I). Su empleo dependía de la pieza a modelar. Reproducción esquemática de Adrián R. Peralta Chacón, tomado de Suárez, I780. 
cortaba el cilindro a lo largo por una de sus caras, lo que generaba que la estructura tendiera a tomar forma cóncava con tendencia a aplanarse a causa del peso de sus borde. Mediante pinzas colocadas en sus vértices se ubicaba sobre una plancha de piedra o madera, cubierta de una capa de arena o polvo muy fino para evitar su adherencia a la superficie ${ }^{54}$ y completar su aplanamiento; debido a que los cilindros de vidrio eran cortos y de diámetro reducido, las placas de vidrio empleadas como ventanas o espejos eran de dimensiones reducidas. También se elaboraba vidrio plano de forma circular a partir del aplanamiento de la vejiga ${ }^{55}$ al presionarla sobre la plancha mencionada.

Los candiles o arañas se conformaban de piezas pequeñas de diversas formas, las que se perforaban con pinzas de extremos puntiagudos para generar orificios pequeños e introducir cordón de metal para unirlas entre sí, en algunas de ellas se generaban realces en la superficie al presionarlas con pinzas de relieve en las caras internas o bien eran labradas a mano.

Las bases planas de vasijas y recipientes se generaban con el uso de placas de mármol o metal denominadas "mabre" o "plancha”, al asentar la vejiga de vidrio; de requerirse algún detalle de dimensión en una porción del objeto, el artífice se auxiliaba del "bufador" (Fig. 6) ${ }^{56}$, herramienta con la que se insuflaba aire en una porción de la pieza fija al "puntil", generalmente eran recipientes de forma particular solicitados por boticarios y médicos. Los objetos ya modelados se separaban de este para introducirlos al horno de enfriamiento o templador mediante el uso de palas largas a manera de charolas; para desplazarlas en el interior se empleaba el "rable", varilla de madera y hierro en forma de "T", la porción más larga servía de mango.

De todo lo anterior se deduce que el espacio físico destinado a la fabricación de vidrio era de dimensión extensa ya que aunado al asignado a los hornos se requería de sitios adicionales para molienda de la materia prima, sí el material no se adquiría con cierto grado de trituración, lugar para el resguardo de herramientas, accesorios y el destinado a almacenar materia prima, leña

54 Cortés (2001, pp. 10-19).

55 Suárez y Núñez (1780, t. IV, pp. 222-224).

56 Cañabate (1958, p. 66); Suárez y Núñez (1780, t. IV, pp. 222-224). 

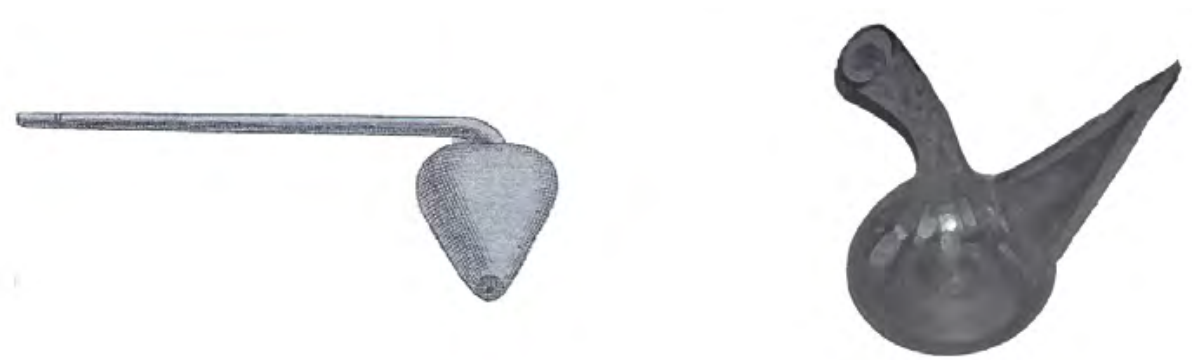

Fig. 6 La ilustración izquierda corresponde a la herramienta denominada "bufador", utilizada para soplar dentro de la pieza modelada parcialmente y así dar forma a porrones bufados, ilustración de la derecha. Fuentes: Cabañete, I958, Suárez y Núñez, I780.

y piezas producidas. Era costumbre que el sitio de fabricación se ubicara adjunto a la morada del maestro vidriero, por lo que todo induce a pensar que aún de que el taller de producción fuera pequeño dispusiera recursos mínimos para laborar. Existe registro de que se asignó a uno de los primeros vidrieros novohispanos dos "solares", terreno con superficie total de 5000 varas cuadradas equivalente a $3,512 \mathrm{~m}^{2}$, en donde podría construir su vivienda y taller, asimismo de que a otro vidriero se le concedió un solar en el barrio de Moyotla, localizado al sur-poniente de la ciudad ${ }^{57}$. La ubicación de los sitios de fabricación de vidrio en la ciudad de México era contigua a las acequias por la necesidad imperiosa de agua en el proceso y asimismo como vía de acceso para la entrega de materia prima y leña proveniente de bosques circunvecinos; su localización alejada de la ciudad prevenía incendios y otras molestias, sin embargo el apresurado asentamiento de la población condujo a su inclusión en la parte urbana, lo que sucedió con la Casa del Apartado.

La labor de producción vidriera era compleja y detallada, la instalación de la planta productiva implicaba recursos económicos de consideración aún de ser modesta. En forma específica la Casa del Apartado, a cargo de particulares, pudo hacer frente a la inversión ante los altos ingresos obtenidos por la separación del oro y plata, que el gobierno pagaba por ello. Este sitio de

57 O’Gorman (1970, p. 385); Boehm (1987, p. 62). 
producción absorbía la "barrilla" y el tequesquite de la más alta calidad para producir cornamuzas y agua fuerte, destinados a la separación de los metales referidos; ante la experiencia alcanzada y el aprovechamiento de la infraestructura instalada se dedicó a producir envases y otros aditamentos de vidrio para boticarios y médicos, lo que redundaba económicamente. Para los vidrieros independientes que atendían la demanda de algunos miembros de la sociedad de boticarios y flebotomianos, la instalación del sitio de producción fue más ardua, muy probablemente tuvieron que recurrir ocasionalmente a la Casa referida para adquirir barrilla o bien a la Real Fábrica de Pólvora para procurarse tequesquite, puesto que esta última supervisaba el uso de la variante refinada.

A pesar de lo anterior el proceso de producción de vidrio en la ciudad de México, que tuvo como fundamento la experiencia peninsular, se enfocó a la fabricación de artículos suntuarios de uso cotidiano y hacia la elaboración de recipientes empleados en la metalurgia y iatroquímica, (etapa de transición entre la alquimia y química farmacéutica), el uso de envases contenedores de remedios para la salud muy probablemente fueron incorporándose a la vida cotidiana para ser de uso ordinario en aquellos ámbitos sociales carentes de capacidad económica para encargarlos al artesano.

\section{ARCHIVOS}

- Archivo General de la Nación.

- Archivo General de Notarias de México

- Archivo Histórico del Estado de México.

\section{BIBLIOGRAFÍA}

- Acuña, R. (1987). Relaciones Geográficas del Siglo XVI. Michoacán. México: Universidad Nacional Autónoma de México.

- Agricola, G. (1950), De Re Metallica Libri XII. 1556. Traducción del latín al inglés por H. H. Clark y H. L. Henry. New York: Dover Publications Inc.

- Álvaro Zamora, M. I. (1988). La alfarería y producción de pólvora en Villafeliche (Zaragoza): su interrelación y proyección hacia América (Nueva España). Artigrama 5, 167-184. 
- Barba L. A., F.L. Córdova (1999). Estudios energéticos de la producción de cal en tiempos teotihuacanos y sus implicaciones”. Latin American Antiquity 10 (2), 168-179.

- Bargalló, M. (1966). La química orgánica y el beneficio de los metales en el México Prehispánico y Colonial. México: Universidad Nacional Autónoma de México.

- Boehm de Lameiras, B. (1987). El municipio en México. México: El Colegio de Michoacán.

- Bohumil, B. (1964). Apuntes sobre los orígenes del comercio vidriero entre Bohemia y México (1787-1839). En Historica IX, Separatum. Praga 1964. Nakladatelstivi Ceskoslovenske Akademievéd. Traducción de E. Roldán Roman, 24-26.

- Cadiñanos Bardeci, I. (1999). Unas ordenanzas de los plateros de Valladolid en el siglo XVIII. Boletín del Seminario de Estudios de Arte y Arqueología 65, 371-387.

- Cañabate Navarro, E. (1958). Vidrios Cartageneros del siglo XIX. España: Murcia Suc. de Nogués.

- Carrera Pujal, J. (1944). Historia de la Economía Española. Barcelona, España: Bosch.

- Castillo Cárdenas, K. (2007). Alfareros, consumo y simbolismos: la producción de lozas vidriadas en la ciudad de México y su papel en la sociedad virreinal. Tesis de Licenciatura en Arqueología. Universidad de las Américas. Puebla.

- Castro Morales, E. (2004). Loceros poblanos, su gremio, ordenanzas y hermandad. Boletín de Monumentos Históricos, Tercera Época, 51-68.

- Coll Conesa, J., A. García Porras. Tipología, cronología y producción de los hornos cerámicos en al_Andalus. http://www.arqueologiamedieval.com/ articulos/125/tipologia-cronologia-y-produccion-de-los-hornos-ceramicos-en-al-andalus. Consultada 20 de junio de 2016.

- Corpancho, M. N. (1862). Geografía del Perú: Obra póstuma del D.D. Mateo Paz Soldán. Paris: Farmín Didot Hermanos.

- Cortés Pizano, F. (2001). Breve historia de las aplicaciones del vidrio plano en la construcción. Revista del Vidrio Plano 42, 10-19.

- De Herrera, G. A. (1818). Agricultura General. Madrid: Imprenta Real.

- Humbolt, A. von (2004). Ensayo Político sobre el Reino de la Nueva España. México: Porrúa. 
- De Odriozola, M. (1872). Colección de documentos literarios del Perú. Lima, Perú: Tipografía y Encuadernación Aurelio Alfaro.

- De Valle Arizpe, A. (1961). Notas de Platería. México: Herrero Hermanos.

- Del Río, A. M. (1795). Elementos de orictognosia o del conocimiento de los fósiles. Impresos en México por Mariano Josfh de Zúñiga y Ontiveros.

- Díaz del Castillo, B. (2002). Historia Verdadera de la Conquista de la Nueva España. México: Porrúa.

- Dihigo, J. M. (1946). Léxico cubano: Contribución al estudio de las voces que lo forman. La Habana, Cuba: Selecta.

- Don J. P. y A. (1900). Plantas de Monte. Madrid: A. Larbaletrier.

- Eguilaz y Yanguas, L. (1886). Glosario etimológico de las palabras españolas (castellanas, catalanas, gallegas, mallorquinas, portuguesas, valencianas y vascongadas) de origen oriental (árabe, hebreo, malayo, persa y turco). Granada, España: La Lealtad.

- Elcano, J. S. (1940), Estudios Geográficos. España: Instituto de Economía y Geografía Aplicadas.

- Fernández Pérez, J. (2002). Algunas especies vegetales de uso industrial en la época romana. Artifex: Ingeniería romana en España. Madrid, España: Museo Arqueológico Nacional/Ministerio de Educación, Secretaría General Técnica.

- Fernández Pérez, J. (1998). La elaboración de la sosa en España: de la barrilla a la fábrica Solvay de Torrelavega Antila. Revista de Historia de las Ciencias de la Naturaleza y la Recnología IV (1).

- Flores Clair, E. (2006). Los progresos de la fundición de metales argentíferos en la minería novohispana del siglo XVIII. Dimensión Antropológica 36, 43-62.

- Garcés y Erguía, J. (1802). Nueva teoría y práctica del beneficio de los metales de oro y plata. México: Oficina de Mariano de Zuñiga y Ontiveros.

- Gibson, C. (1997). Los aztecas bajo el dominio español 1519-1810. México: Siglo XXI.

- Gutiérrez Castorena, M. C., G.G. Stoops, S.A. Ortiz (1998). Carbonato de calcio en los suelos del ex lago de Texcoco. Terra 16 (1), 11-19.

- Herrejón Peredo, C. (2000). Los orígenes de Morelia: Guyangareo-Valladolid. México: El Colegio de Michoacán. 
- Jiménez Castillo, P., J. Navarro Palazon, J. Thiriot . (1998). Taller de vidrio y casas andalusíes en Murcia. Excavación arqueológica del Casón de Puxmarina. Memorias de Arqueología 13, 419-458.

- Lister Florence, C. and R. H. (1982). Sixteenth century maioloca pottery in the valley of Mexico. The anthropolofical papers of the University of Arizona 39.

- Lombardo de Ruiz, S. (1973). Desarrollo urbano en México-Tenochtitlan según las fuentes históricas. México: Secretaría de Educación Pública/Instituto Nacional de Antropología e Historia.

- Martínez, M. (1979). Catálogo de nombres vulgares y científicos de plantas mexicanas. México: Fondo de Cultura Económica

- Mazadiego Martínez, L. F., O. Puche Riart, L. Canoira López y J.F. Llamas Borrajo (2006). Los hornos de vidrio de D. Ramón Sáez en Cadalso de los Vidrios (Madrid). De Re Metallica 6-7, 67-74.

- Muñoz López, F. (1999). Algunos aspectos del zoco de la Murcia Islámica, excavación de un solar de calle Polo de Medina esquina con Plaza de Belluga. Memorias de Arqueología 14, 459-474.

- ÓGorman, E. (1970). Guía de los Archivos de Cabildo de la Ciudad de México Siglo XVI. México: Fondo de Cultura Económica.

- Palma, L. V. (2010). Historia de la producción de cal en el norte de la cuenca de México. CIENCIA ergo16 (3), 227-234.

- Pastor Rey de Viñas, P. (1994). Historia de la Real Fábrica de Cristales de San Ildefonso durante la Época de la Ilustración (1724-1810). España: Fundación Centro Nacional del Vidrio/Consejo Superior de Investigación Científica y Patrimonio Nacional.

- Paz Soldan, M. (1862). Geografía del Perú. Lima, Perú: Publicada a expensas del Gobierno Peruano.

- Peralta Rodríguez, J. R. (2011). El vidrio en la ciudad de México. Productores y productos novohispanos. Siglos XVI-XVIII. Alemania: Académica Española.

- Peralta Rodríguez, J. R. (2014). Boticarios, Boticas y Vidrieros en la Nueva España, ciudad de México siglo XVI. Acta Médica Politécnica 2 (2), 73-79.

- Peralta Rodríguez, J. R., M.J. Alvizar Rodríguez. (2010). El vidrio en la Casa del Apartado, siglos XVI-XVIII. Procesos Históricos18. 
- Rodríguez García, J. (1989). Algunas noticias sobre una fábrica de vidrio de Venecia en San Martín Valdeiglesias (1679-89). Espacio, Tiempo y Forma. Serie IV. Historia Moderna 2, 155-174.

- Roig y Mesa, J. T. (1928). Diccionario botánico de nombres vulgares cubanos. La Habana, Cuba: Imprenta y Papelería de Rambla, Bonza y Ca.

- Santamaría, F. J. (1943). Diccionario General de Americanismo. México: Pedro Robledo.

- Sala Cajal, L. (2003). La competencia terminológica: causas lingüísticas en el auge del término sosa y declive de barrilla en los siglos XVIII-XIX. Asclepio 55 (2), 67-92.

- Suárez y Núñez, G. M. (1780). Memorias instructivas y curiosas sobre agricultura, comercio, industria, economía, química, botánica, historia general. Madrid: Pedro Marín.

- Talavera Bernad, E. E. (1990). Las salinas en la cuenca de México y la cerámica de impresión textil. Tesis de licenciatura en Antropología especialidad en Arqueología. Universidad Nacional Autónoma de México.

- Teófilo. (2002). Las Diversas Artes. Tratado medieval sobre pintura, trabajo en vidrio y metalistería. México: Ediciones La Rana.

- Townsend, J. (1792). A Journey through Spain. London: Printed for Dilly in the Poultry.

- Velasco Hernández, F. (2004). La sosa-barrilla: una seña de identidad del campo de Cartagena en los siglos XVI al XIX. Revista Murciana de Antropología 10, 45-158. 